\title{
专题：地球生物学前沿
}

论 文

\section{细菌群落在神农架大九湖泥炭藓与表层沉积物的 垂向变化及其生态意义}

\author{
向兴，王红梅*，龚林锋，刘乔 \\ 中国地质大学生物地质与环境地质国家重点实验室, 武汉 430074 \\ * 联系人, E-mail: hmwang@ @ug.edu.cn
}

收稿日期: 2013-07-15; 接受日期: 2013-09-10; 网络版发表日期: 2014-05-12

国家自然科学基金项目(批准号：41130207，41072253)和中央高校基本科研业务费专项资金(编号：CUG090103，CUGL100502，CUG120103) 资助

\begin{abstract}
摘要为了探讨泥炭藓共生细菌和泥炭表层沉积物细菌群落的垂向变化以及它们在湿地生 态系统中的作用，对大九湖泥炭湿地泥炭藓植株的不同部位和下伏泥炭沉积物进行了分层采 样. 利用克隆文库和荧光定量 PCR 技术对样品中的细菌进行了定性和定量分析. 结果表明, 尽管细菌的 $16 \mathrm{~S}$ rRNA 基因拷贝数在同一个数量级 ( $10^{8}$ 个拷贝/克样品), 并以变形菌和酸杆菌 占优势, 但细菌群落组成由泥炭藓上部至下部再到泥炭沉积物不同深度存在显著的空间变化. 泥炭藓上部以蓝细菌(Cyanobacteria)和 $\alpha$ 变形菌门(alpha-Proteobacteria)为主, 中部则以酸杆菌 门(Acidobateria)为主, 泥炭藓下部和最表层泥炭以 $\alpha$ 变形菌门和酸杆菌门为主, 地表以下的泥 炭样品以酸杆菌门占优势. 细菌组成的这种空间分布规律与细菌的生态功能密切相关. 泥炭 藓上部的蓝细菌通过光合作用与泥炭藓共生. 酸杆菌门的细菌一方面能适应泥炭湿地低 $\mathrm{pH}$ 的 环境条件, 另一方面还在泥炭藓植株的降解及泥炭的形成中发挥重要作用, 并可能参与泥炭 湿地酸性条件的形成。在泥炭藓不同部位均发现了甲基胞囊菌科(Methylocystaceae)的克隆, 暗示甲烷氧化不仅局限于泥炭藓死亡的透明细胞中, 而是在泥炭藓的整个植株中均可能存在 着活跃的甲烷氧化过程. 这一工作对深刻理解和定量研究泥炭地的微生物地球化学过程, 特 别是甲烷通量以及甲烷循环具有重要意义.
\end{abstract}

关键词

大九湖 泥炭藓 泥炭沉积物 细菌群落 甲烷循环
泥炭地作为典型的湿地生态系统, 覆盖了全球 $3 \%$ 的陆地面积, 储存了高达 30\%的陆地碳, 在碳循环 中扮演着重要的角色(Gorham, 1995). 由于较低的 $\mathrm{pH}$ 和较高的地表水位或地面径流产生的厌氧环境, 净初 级生产力对碳的封存量远远超过有机质分解向大气中 释放的 $\mathrm{CO}_{2}$ (Augustin 等, 1996), 因此被认为是大气
$\mathrm{CO}_{2}$ 永久的碳汇和全球的碳库. 北半球泥炭地拥有 200 450 Pg 碳, 约占全球土壤碳汇的 1/3 (Gorham, 1991). 根据理化性质, 泥炭湿地分为三个营养级: 富 营养、中营养和寡营养(Bridgham 等, 1996). 大部分泥 炭湿地是以泥炭藓为主的寡营养泥炭沼泽, 矿质营养 主要来自大气沉降, 而泥炭湿地的生物地球化学过程

中文引用格式: 向兴, 王红梅, 龚林锋, 等. 2014. 细菌群落在神农架大九湖泥炭藓与表层沉积物的垂向变化及其生态意义. 中国科学: 地球科学, 44: $1244-1252$

英文引用格式: Xiang X, Wang H M, Gong L F, et al. 2014. Vertical variations and associated ecological function of bacterial communities from Sphagnum to underlying sediments in Dajiuhu Peatland. Science China: Earth Sciences, 57: 1013-1020, doi: 10.1007/s11430-013-4752-9 
则被认为主要由泥炭藓来调节(Pankratov 等, 2008).

值得注意的是, 微生物作为地球上生物地球化 学的引擎(Falkowski 等, 2008), 近年来在泥炭湿地的 形成和生态功能研究中引起了人们的关注, 研究范 围涵盖了北半球寒温带西伯利亚泥炭沼泽(Dedysh 等, 2006)、热带马来西亚沼泽森林(Jackson 等, 2009)和南 半球亚马逊泥炭土(Kim 等, 2007)等地. 各地细菌群 落结构存在显著的差异, 如 Ausec 等人(2009)发现卢 布尔雅那泥炭沉积物细菌群落以酸杆菌门占优势; 而西伯利亚泥炭沼泽酸杆菌门和变形菌门克隆子相 当, 荧光原位杂交技术则揭示 $\alpha$ 变形菌和浮霉菌是数 量最多的两个类群(Dedysh 等, 2006). 关于与泥炭藓 共生的微生物也有报道, 如 Kip 等人(2012)研究了巴 塔哥尼亚泥炭藓共生的细菌群落组成, 结果显示细 菌群落中变形菌门最丰富, 酸杆菌门和浮霉菌门位 于第二和第三. 刘乔等人(2013)对大九湖泥炭藓植株 进行了不同的预处理, 并利用克隆文库以及定量 PCR 的技术对泥炭藓内、外共生细菌群落结构进行 了研究. 结果表明, $\mathrm{H}_{2} \mathrm{O}_{2}$ 能有效地破坏泥炭藓外共生 细菌的 DNA, 从而有效地区别泥炭藓内共生和外共 生细菌的群落组成. 泥炭藓内共生的细菌表现出很 强的环境适应能力, 对大九湖泥炭湿地酸性、寡营养 等环境条件显示出高度的适应性(刘乔等, 2013), 并 推测这些共生细菌还能有效地参与泥炭湿地的碳循 环. Raghoebarsing 等人(2005)则对细菌参与泥炭湿地 碳循环做了直接的证明. 他们通过苂光显微镜、透射 电镜等观察和泥炭藓培养实验 (以 ${ }^{13} \mathrm{C}$ 标记的甲烷为 底物), 发现泥炭藓表层透明细胞及茎叶上具有成簇 的 II 型嗜甲烷菌. 这些细菌能将甲烷氧化成 $\mathrm{CO}_{2}$, 而 $\mathrm{CO}_{2}$ 可作为泥炭藓光合作用的底物, 被进一步转化为 甾醇类化合物. 通过这个途径, $\mathrm{CH}_{4}$ 可以为泥炭藓提 供大约 10\% 15\%的碳源 (Raghoebarsing 等, 2005). 事 实上, 泥炭藓样品中普遍存在甲烷的氧化, 并且甲烷 氧化强度与样品采集点的甲烷浓度正相关 (Kip 等, 2012).

前人对泥炭沉积物以及泥炭藓共生细菌做了开 创性的工作, 对认识泥炭湿地的元素循环和微生物 与泥炭藓的共生关系起到了重要的推动作用. 但是, 由于泥炭藓生长的营养主要来自于大气沉降, 泥炭 藓上部生长的同时, 伴随着下部的衰老、死亡, 而泥 炭湿地的缺氧环境使泥炭藓下部的死亡残体直接碳 化(包文美和曹建国, 2001), 从而构成旺盛生长的泥
炭藓-衰老/死亡的泥炭藓-泥炭沉积物的有机整体. 研究泥炭藓植株不同部位和泥炭沉积物不同深度样 品中细菌的群落组成, 可以清楚地追踪泥炭藓生长、 衰老、死亡和碳化整个过程中细菌群落组成的变化, 对动态理解泥炭湿地的元素循环具有十分重要的意 义. 遗憾的是, 目前这方面的工作还极其欠缺.

大九湖泥炭湿地 $\left(31^{\circ} 28^{\prime} 50^{\prime \prime} \mathrm{N}, 110^{\circ} 00^{\prime} 90^{\prime \prime} \mathrm{E}\right)$ 属于 典型的以泥炭藓为主的寡营养泥炭沼泽地, 地处神 农架边缘, 面积 $16 \mathrm{~km}^{2}$, 海拔 $1700 \mathrm{~m}$. 泥炭沉积物厚 度超过 $2 \mathrm{~m}$, 是亚洲典型的亚高山泥炭湿地, 在全球 变化、古气候和生物多样性研究中均具有极其重要的 地位. 前人对该地区的狍粉(何报寅等, 2003; 朱诚等, 2006; 石敏等, 2008)和类脂物(Huang 等, 2011; Xie 等, 2013)等的研究均取得了重要认识, 为古气候演化和 环境重建提供了有力的证据. 但对该地区微生物现 代过程的研究仍十分薄弱. 虽然我们前期对泥炭藓 内共生菌和表面共生菌进行了研究(刘乔等, 2013), 但对于泥炭藓生长、衰老/死亡和沉积成碳等过程中 细菌群落的变化没有论述. 针对这一问题, 本研究对 泥炭藓的不同部位和下伏不同深度的沉积物进行采 样, 通过构建克隆文库和荧光定量 PCR 方法分析微 生物的群落结构和丰度, 探讨泥炭藓生活过程中微 生物的动态变化, 以期更加详细而准确地理解泥炭 湿地中微生物参与下的元素循环.

\section{1 材料与方法}

\section{1 样品采集}

采样点位于神农架大九湖泥炭地, 采样时间为 2012年 11 月的枯水期, 水位在地表以下 $15 \mathrm{~cm}$ 处. 采 样时, 选取整个泥炭藓植株以及泥炭藓所在地不同 深度的泥炭沉积物作为研究对象. 泥炭藓茎长 $15 \mathrm{~cm}$ 左右，根据颜色分为上、中、下三段，上段为绿色，中 段颜色偏淡, 下段为褐色, 分别命名为 SP1, SP2 和 SP3; 下伏泥炭沉积物样品分别位于距地表 0,5 和 25 $\mathrm{cm}$ 深处, 依次命名为 SD1, SD2 和 SD3. 采样所用器 具均经高压灭菌, 采样时配戴一次性手套, 样品用 $50 \mathrm{~mL}$ 无菌离心管保存. 样品采集后迅速放入 $4^{\circ} \mathrm{C}$ 保 温箱带回实验室，放入 $-80^{\circ} \mathrm{C}$ 冰箱保存备用.

\subsection{DNA 的提取}

将少量样品冷冻干燥后用研针充分研磨, 用土 
壤 DNA 提取试剂盒(Fast DNA Spin kit for soil, 美国 MP 公司)提取样品基因组 DNA, 并检测 DNA 的浓度 及纯度(Nanodrop 2000, Thermo 公司). 由于泥炭样品 中腐殖质含量较高, 且其对后续的 PCR 具有抑制作 用, 因此提取后的 DNA 需要进行纯化. 所用试剂为 Binding buffer(QIAGEN 纯化试剂盒, 德国), 纯化后 的 DNA 放入 $-20^{\circ} \mathrm{C}$ 冰箱备用.

\section{3 苂光定量 PCR}

将基因组 DNA 利用细菌通用引物 $331 \mathrm{~F}$ 和 797 $\mathrm{R}$ (Nadkarni 等, 2002)进行荧光定量扩增. 反应体系为 2×TaKaRa 预混合液 $10 \mu \mathrm{L}, 331 \mathrm{~F}(20 \mu \mathrm{M}) 0.5 \mu \mathrm{L}, 797$ $\mathrm{R}(20 \mu \mathrm{M}) 0.5 \mu \mathrm{L}$, DNA 模板 $2 \mu \mathrm{L}$, 用无菌水补至 20 $\mu \mathrm{L}$. 扩增条件为: $95^{\circ} \mathrm{C} 30 \mathrm{~s}, 95^{\circ} \mathrm{C} 1 \mathrm{~s}, 62^{\circ} \mathrm{C} 30 \mathrm{~s}$, $72^{\circ} \mathrm{C} 1 \mathrm{~min}$, 每次延伸结束时检测荧光强度. 溶解曲 线分析程序为: $95^{\circ} \mathrm{C} 1 \mathrm{~s}, 65^{\circ} \mathrm{C} 15 \mathrm{~s}$, 每秒升温 $0.5^{\circ} \mathrm{C}$ 并 进行荧光采集, 达到 $95^{\circ} \mathrm{C}$ 保持 $5 \mathrm{~s}$. 标准品质粒来自 于测序时获得的质粒样品, 由南京金斯瑞生物科技 有限公司提供.

\section{4 克隆文库的构建}

选取细菌的通用引物对 $27 \mathrm{f}$ 和 $1492 \mathrm{r}$ (Gürtler 和 Stanisich, 1996)/907 r(Muyzer 和 Smalla, 1998)进行 PCR 扩增. 反应的体系为 $25 \mu \mathrm{L}: 10 \times \mathrm{PCR}$ 缓冲液 2.5 $\mu \mathrm{L}, \mathrm{Mg}^{2+}(25 \mathrm{mM}) 2.0 \mu \mathrm{L}, \quad \operatorname{dNTP}(2.5 \quad \mathrm{mM}) 2.0 \mu \mathrm{L}$, $\operatorname{BSA}\left(20 \mu \mathrm{g} \mu \mathrm{L}^{-1}\right) 1.0 \mu \mathrm{L}, 27 \mathrm{f}(20 \mu \mathrm{M}) 0.5 \mu \mathrm{L}, 1492 \mathrm{r}$ (或 907r $20 \mu \mathrm{M}) 0.5 \mu \mathrm{L}$, Taq 酶 $\left(5 \mathrm{U}^{-1} \mathrm{~L}^{-1}\right) 0.25 \mu \mathrm{L}, \mathrm{dd}_{2} \mathrm{O}$ 补足至 $25 \mu \mathrm{L}$. 扩增程序为 $94^{\circ} \mathrm{C}$ 预变性 $5 \mathrm{~min}, 94^{\circ} \mathrm{C}$ 变 性 $30 \mathrm{~s}, 55^{\circ} \mathrm{C}$ 退火 $45 \mathrm{~s}, 72^{\circ} \mathrm{C}$ 延伸 $1 \mathrm{~min}, 36$ 个循环, $72^{\circ} \mathrm{C}$ 延伸 $10 \mathrm{~min}$. 对 PCR 产物纯化后(QIAquick gel Extraction kit, QIAGEN 公司)链接到 pMD18-T 载体 (TaKaRa 公司)上, 之后将重组质粒转入 Escherihcia coli JM109 菌株. 在含有氨苄青霉素, X-gal 和 IPTG 的琼脂糖平板培养基培养(培养条件: $37^{\circ} \mathrm{C}, 12 \sim 16 \mathrm{~h}$ ), 进行蓝白斑篎选, 挑取阳性克隆由南京金斯瑞生物 科技有限公司进行测序.

所获序列经过 NCBI Vescreen(http://www.ncbi. nlm.nih.gov/tools/vecscreen/)载体污染检测后, 共获 取有效序列 396 个, 每个样品包含 60 80个序列. 随后 对所有样品进行 NCBI blast (http://blast.ncbi.nlm.nih.gov/ Blast.cgi?PROGRAM=blastp\&BLAST_PROGRAMS= deltaBlast\&PAGE_TYPE=BlastSearch) 分析, 搜索参
考序列, 利用 MEGA5.0 比对参考序列(http://www. megasoftware.net/), 利用 Phylogeny-Neighbor-Joining (NJ)方法构建系统发育树.

\section{5 细菌群落多样性指数的计算}

使用 DOTUR 软件 (dotur.exe, http://www. plantpath.wisc.edu/fac/job/dotur.html), 以进化距离 $\leqslant 0.03$ (序列相似性 $\geqslant 97 \%$ )的 $16 \mathrm{~S}$ rRNA 序列作为一个 操作分类单元(operational taxonony unit, OTU), 在此 基础上计算克隆文库的多样性指数. 多样性包括稀 释曲线(Heck 等, 1975), 香农维纳指数 H(Shannon Wiener), 辛普森指数 D 和 Chao1 指数(Chao, 1984). 稀释曲线用于不同位点、不同处理或不同环境下样品 多样性比较. 香农维纳指数与物种的丰度度和均匀 度呈正相关, 对稀有物种丰度的改变很敏感. 辛普森 指数是指样品中随机挑选两个克隆子是同一物种的 几率(Hughes 等, 2001). 由于辛普森指数和多样性呈 负相关, 故文中使用了辛普森指数的倒数 $(1 / \mathrm{D})$, 该 值随着群落多样性增加而增加. Chao1 指数估计样品 中微生物群落总的丰富度, 通常利用置信区间反应 存在的变异(Wang 等, 2005). 样品的覆盖度根据公式 (1)(Humayoun 等, 2003)进行计算:

$$
R_{\mathrm{cov}}=1-(S / N) \text {, }
$$

式中, $S$ 为 OTU 的个数, $N$ 为克隆子数目.

\section{2 结果}

\section{1 细菌 $16 \mathrm{~S}$ rRNA 基因丰度}

荧光定量结果表明, 所有样品的细菌 16S rRNA 基因丰度均在 $10^{8}$ 个拷贝/克样品(图 1). 表明泥炭藓 植株以及泥炭沉积物中均含有丰富的微生物. 整体 来看, 泥炭藓生长部分(SP1 和 SP2)的基因丰度最低, 衰老/死亡部分(SP3 和 SD1)的基因丰富最高，两者相 差 2.8 倍.

\section{2 细菌群落多样性}

样品的细菌群落多样性很高, 各个样品的覆盖 度较低(22\% 54\%)(表 1). Chao1 指数比实际获取的克 隆数目多, 且稀释曲线未达到饱和(图 2). 因此克隆 文库只能反映细菌群落组成的部分信息.

通过比较不难发现, SP1 细菌多样性最低(表 1), 香农维纳指数为 2.85 , 辛普森指数的倒数为 7.85 . 


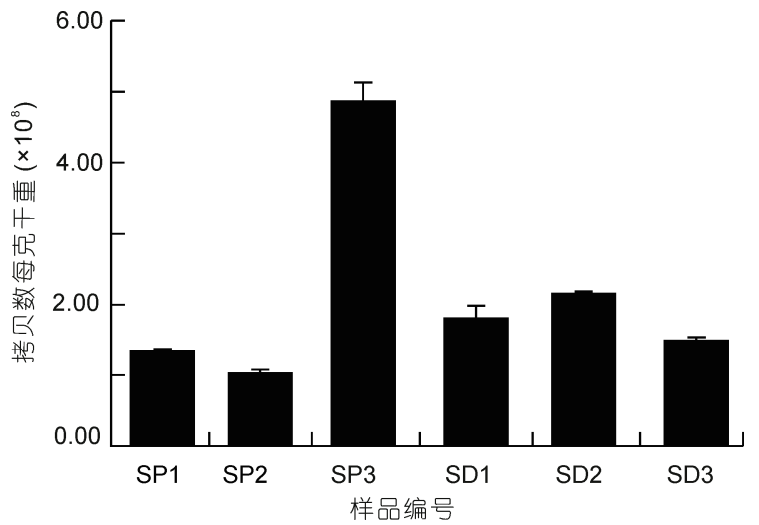

图 1 大九湖泥炭藓及下伏泥炭沉积物样品细菌 16S rRNA 基因拷贝数

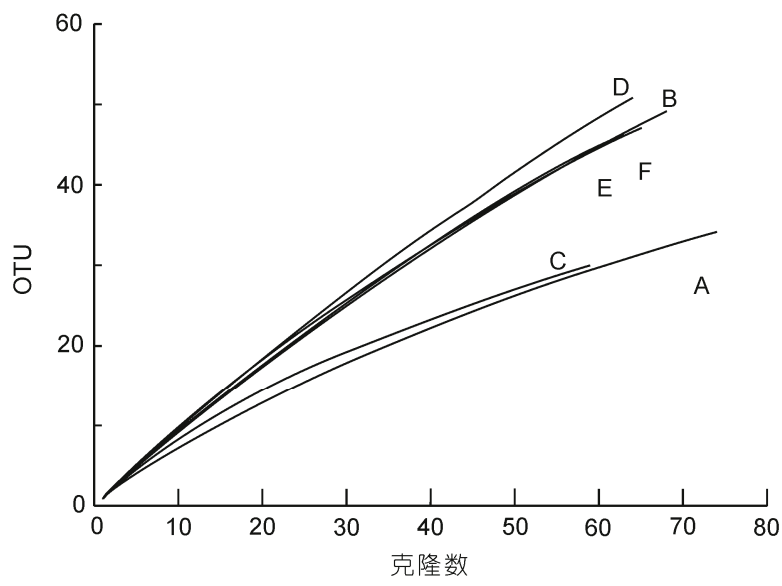

图 2 大九湖泥炭藓 $(\mathrm{A}, \mathrm{B}, \mathrm{C})$ 及下伏泥炭沉积物细 $(\mathrm{D}, \mathrm{E}, \mathrm{F})$ 菌克隆文库的稀释曲线

$\mathrm{SD} 1$ 多样性最高, 香农维纳指数为 3.84 , 辛普森指数 的倒数为 112. 总体来看, 沉积物的细菌群落多样性 较泥炭藓的高. 沉积物细菌群落的香农维纳指数均 在 3.6 以上, 辛普森指数的倒数均在 49 以上, Chao1 指数也都大于 95 . 泥炭藓样品(除 SP2)的香农维纳指 数在 3 左右, 辛普森指数的倒数均在 25 以下, Chao 1
指数在 $50 \sim 60$ (表 1).

\section{3 细菌群落组成}

所获得序列共分属于 14 个门类(图 3), 其中变形 菌门(Proteobacteria) 是克隆子数目最多的类群, 其次 是酸杆菌门(Acidobacteria), 二者所占比例均在 $35 \%$ 以上. 其他类群所占比例较小, 包括蓝细菌门 (Cyanobacteria)、放线菌门(Actinobacteria)、疮微菌门 (Verrucomicrobia)、拟杆菌门(Bacteroidetes)、浮霉菌 门(Planctomycetes)、绿弯菌门(Chloroflexi)、厚壁菌 门(Firmicutes)、硝化螺旋菌门(Nitrospirae)、芽单胞 菌门(Gemmatimonadetes)、Armatimonadetes、OD1 和 OP11. 这些类群所包含的克隆子占总克隆子的比例 在 10\%以下(图 3).

$\alpha$ 变形菌占了变形菌门克隆子的绝大部分, $\beta, \gamma$ 和 $\delta$ 变形菌门克隆子占总克隆子的比例为 $4 \%$ 左右. 而 $\alpha$ 变形菌门有 5 个亚类(图 4(a)), 其中红螺菌目 (Rhodospirillales)的醋杆菌科(Acetobacteraceae)有 32 个克隆子, 是数量最多的一个科. 同属于根瘤菌目 (Rhizobiales)的慢生根瘤菌科(Bradyrhizobiaceae)和甲 基孢囊菌科(Methylocystaceae)克隆子数目接近, 分 别为 17 和 15 个. 酸杆菌门由三个亚类组成(图 4(b)), subdivision 1 占了绝大部分, 包含 78 个克隆子, subdivision 2 和 3 分别包含了 27 和 31 个克隆子(图 4(b)). 蓝细菌门克隆子大量存在于泥炭藓生长旺盛 的泥炭藓的上部, 在泥炭藓中部及泥炭沉积物底部 也有少量出现.

各样品均含有酸杆菌门和变形菌门, 且二者在 克隆文库中所占比例之和均超过 50\%(SP1 为 $56.8 \%$, 其余样品都超过 70\%). 但各个样品的群落组成(图 3) 存在差异, 优势种类也不尽相同. 蓝细菌门和 $\alpha$ 变形 菌门为 SP1 的优势种类. SP2 中细菌种类最丰富, 包 含 12 个类群, 优势群落是酸杆菌门, 其次为 $\alpha$ 和 $\gamma$ 变 形菌门. 泥炭藓下部的 SP3 和表层泥炭沉积物 SD1

表 1 大九湖泥炭藓及下伏泥炭沉积物中细菌 16S rRNA 基因克隆文库的多样性指数

\begin{tabular}{lcccccc}
\hline 样品编号 & SP1 & SP2 & SP3 & SD1 & 64 & SD2 \\
\hline 克隆子数目 & 74 & 68 & 59 & 32 & 22 & 65 \\
样品覆盖度 $(\%)$ & 54 & 28 & 3.12 & 3.84 & 28 \\
香农维纳指数 $(H)$ & 2.85 & 3.76 & 24.10 & 112.00 & 3.74 \\
辛普森指数的倒数(1/D) & 7.85 & 75.93 & 80.00 & 49.88 \\
Chao1 指数 & $53(40,88)$ & $149(89,298)$ & $59(39,118)$ & $174(102,350)$ & $98(68,170)$ & $154(91,309)$ \\
\hline
\end{tabular}




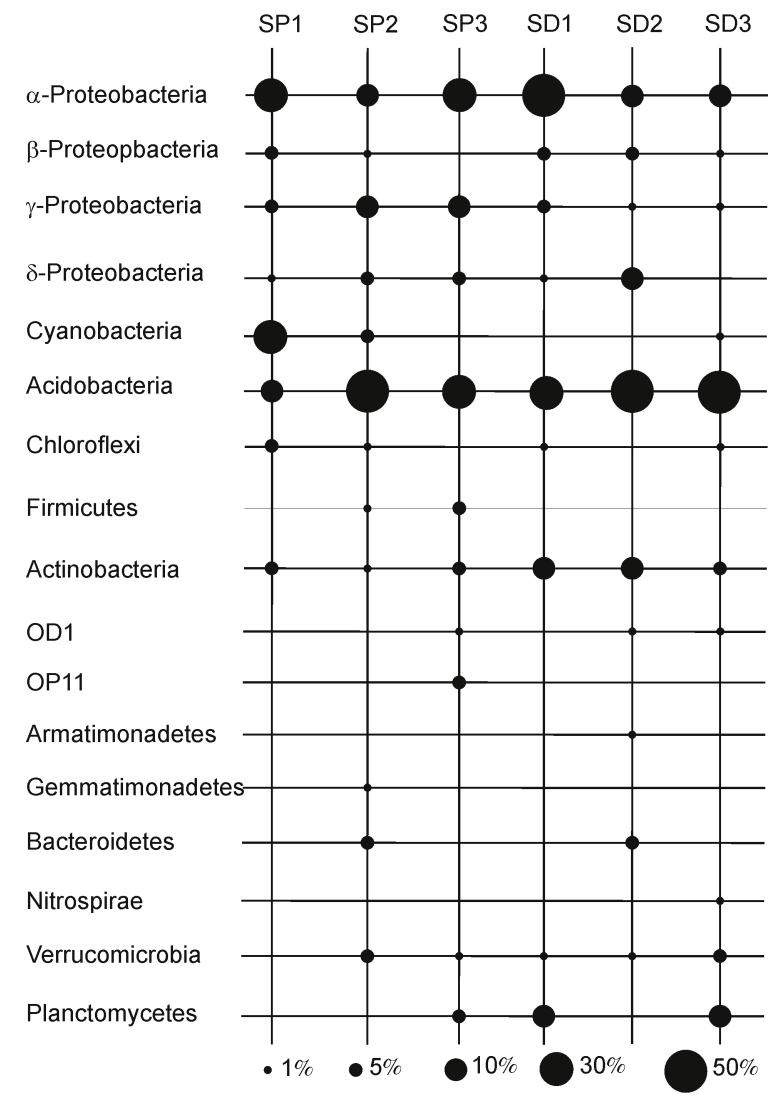

图 3 大九湖泥炭湿地泥炭藓及下伏泥炭沉积物中细菌群 落组成

在细菌群落上比较接近, 均以 $\alpha$ 变形菌门占优势. 不 同深度泥炭沉积物样品 SD2 和 SD3 的细菌群落组成上 比较相似, 均以酸杆菌门为主, 所占比例均在 $50 \%$ 左
右. 但 SD2 中出现的芽单胞菌门(Gemmatimonadetes)、 拟杆菌门(Bacteroidetes)及 Armatimonadetes 克隆子在 $\mathrm{SD} 3$ 中都未发现, 而在 SD3 中却出现了 SD2 中没有 的浮霉菌门(图 3).

\section{3 讨论}

\section{1 与其他泥炭湿地细菌群落结构的比较}

大九湖湿地沉积物细菌群落结构以 $\alpha$ 变形菌门 和酸杆菌门为主, 与其他地区泥炭沉积物中的细菌 群落结构存在显著差异(图 5). 如卢布尔雅那泥炭沼 泽沉积物中 $\alpha, \beta$ 和 $\delta$ 变形菌相对丰度接近, 均在 $11 \% \sim 16 \%$, 而 $\gamma$ 变形菌相对丰度最低(Kraigher 等, 2006; Ausec 等, 2009). 西伯利亚酸性泥炭沉积物中 $\alpha$ 变形菌为优势群落(Dedysh 等, 2006), 且与大九湖泥 炭沉积物中的细菌组成类似, 但是变形菌门只包括 $\alpha$, $\delta$ 两个纲, 种类较简单. 大九湖泥炭藓共生细菌中 $\alpha$ 变形菌克隆子为变形菌门中的优势种, 而新英格兰 地区泥炭沼泽生长的泥炭藓 $\delta$ 变形菌为最丰富的种 类(Morales 等, 2006), 南美的巴塔哥尼亚泥炭沼泽泥 炭藓细菌群落 $\beta$ 变形菌为优势群落(Kip 等, 2012)(图 5). 以上四个泥炭湿地沉积物中的细菌群落均以酸杆 菌和变形菌门为主, 这与 32 个不同类型的土壤细菌 优势群落以变形菌和酸杆菌为主的结论 (Janssen, 2006)吻合. 但变形菌门和酸杆菌门细菌相对丰度的 比值很可能与沉积物的 $\mathrm{pH}$ 有关. 卢布尔雅那泥炭矿 养沼泽 $\mathrm{pH}$ 为 6.6 , 变形菌门与酸杆菌门细菌相对丰度

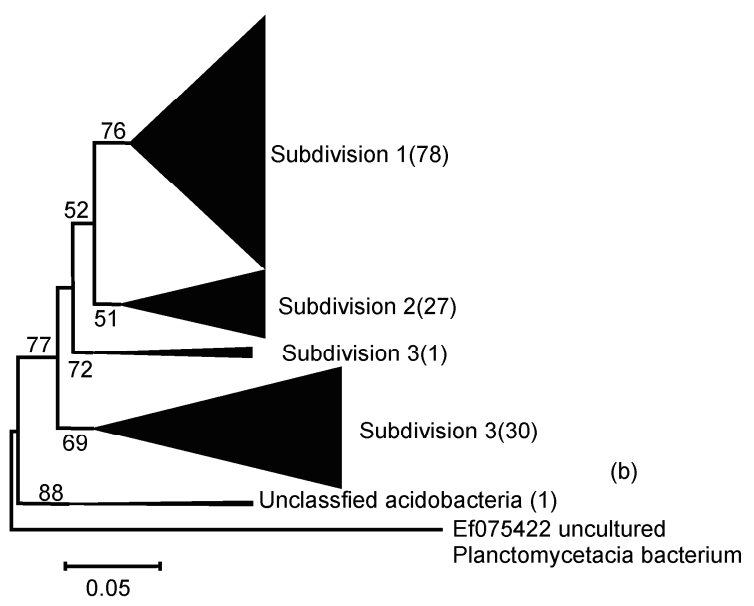

图 4 大九湖湿地泥炭藓及下伏泥炭沉积物中 $\alpha$ 变形菌(a)以及酸杆菌门(b)的系统发育树 括号中数字代表克隆子的数目 


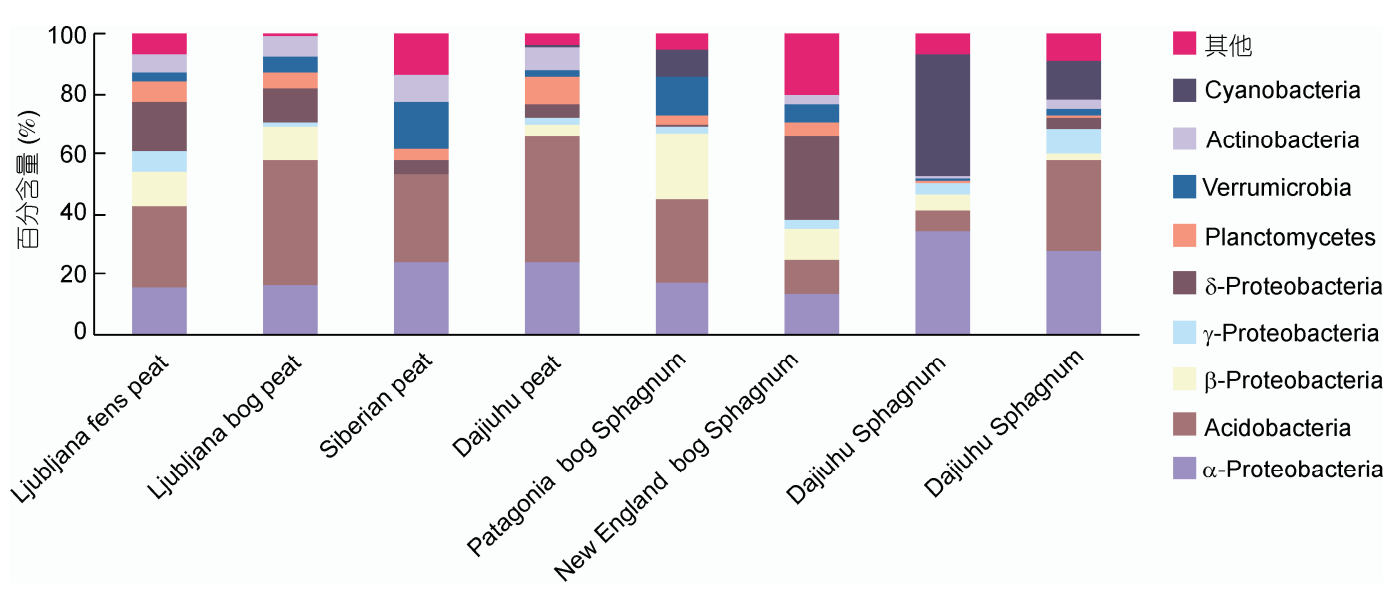

图 5 不同泥炭沉积物和不同泥炭湿地泥炭藓共生细菌群落组成的比较

数据来源自左向右分别为: 卢布尔雅那泥炭沉积物(Kraigher 等, 2006; Ausec 等, 2009)、西伯利亚泥炭沉积物(Dedysh 等, 2006)、大九湖泥炭 沉积物(本文)、巴塔格里亚泥炭藓(Kip 等, 2012)、新英格兰泥炭藓(Morales 等, 2006)、大九湖泥炭藓(刘乔等, 2013)和大九湖泥炭藓(本文)

比值相对较高, 为 1.83 , 而另外三个泥炭地 $\mathrm{pH}$ 较低, 均在 4.5 附近, 变形菌门与酸杆菌门的比值明显降低, 均小于或等于 1 . 对于与泥炭藓共生的细菌群落而言, 变形菌门与酸杆菌门的比值通常大于 1 , 这可能与泥 炭藓共生菌所处的微环境有关. 植物为了维持正常 的新陈代谢(包括三羧酸循环和激素的极性运输), 通 常通过液泡调节(汪良驹和刘友良, 1998)使细胞基质 的 $\mathrm{pH}$ 维持在 7.1 7.5, 呈中性状态(Roberts 等, 1980; Gibbon 和 Kropf, 1993). 因此泥炭藓细胞内中性的 $\mathrm{pH}$ 可能是导致泥炭藓共生菌中变形杆菌门与酸酕菌门 细菌比例较高的重要原因.

\section{2 泥炭湿地细菌群落空间分布的控制因素}

荧光定量结果显示, 所有样品中细菌 16S rRNA 的基因丰度在 $10^{8}$ 个拷贝/克样品(约 $10^{5}$ 个楛贝/纳克 DNA), 较我们之前报道的大九湖泥炭藓共生细菌 $10^{6}$ 个掿贝/纳克 DNA 基因丰度结果 (刘乔等, 2013) 低 1 个数量级, 这可能是季节差异造成的. 之前采样 时间为夏季, 此次采样为冬季. 通常来讲, 冬季比夏 天的微生物数量偏低 (Bossio 等, 1998; 戴雅婷等, 2012). 因此, 环境因子的季节性变化可能对细菌数 量有较大影响.

与中国水稻土(袁红朝等, 2011)细菌 16S rRNA 基因丰度 $\left(10^{10} \sim 10^{11}\right.$ 个拷贝数/克样品)相比, 大九湖 湿地样品中细菌 $16 \mathrm{~S}$ rRNA 基因丰度低 2 3 个数量级. 大九湖湿地样品中的细菌丰度比长期施肥的北方旱
地土壤 $\left(10^{9} \sim 10^{10}\right.$ 楛贝数/克样品, Shen 等, 2010$)$ 低 1 2 个数量级. 尽管大九湖泥炭沉积物中有机碳含量丰 富(总有机碳含量可达 $18.7 \%$, 杨丽阳等, 2009), 但由 于该湿地常年处于低温、饱水状态, 且 $\mathrm{pH}$ 为 4.5 , 这 些环境因子极大地限制了微生物的丰度.

事实上, $\mathrm{pH}$ 对微生物群落的控制和影响在土壤 中已被证实. 据报道, 土壤 $\mathrm{pH}$ 可以反映土壤细菌的 多样性和丰度, 酸性土壤中细菌多样性和丰度最低, 中性环境多样性最高, 碱性环境中细菌多样性居中 (Fierer 和 Jackson, 2006). 此外, 酸杆菌的分布也与 $\mathrm{pH}$ 相关, 当土壤 $\mathrm{pH}$ 为 4.6 5.2 时, 酸杆菌门优势尤 为明显; 而当土壤 $\mathrm{pH}>5.5$, 酸杆菌的丰度急剧降低 (Männistö 等, 2007). 大九湖地区泥炭沉积物的 $\mathrm{pH}$ 在 4.5 左右, 泥炭沉积物中酸杆菌的平均相对丰度为 $42 \%$ (除 SD1 中酸杆菌门相对丰度为 $24 \%$, 另外两个 沉积物样品中酸杆菌门相对丰度均在 $50 \%$ 左右), 为 第一优势类群，与上述土壤 $\mathrm{pH}$ 与酸杆菌的关系吻合. 此外, 在大九湖泥炭沉积物, 我们发现酸杆菌含有丰 富的 subdivision 1, 这与 Sait 等人(2006)报道的酸杆 菌中 subdivision 1 最适合生长于 $\mathrm{pH}<6$ 的土壤环境中 的结论一致. 因此, $\mathrm{pH}$ 可能是影响细菌群落分布的一 个最重要的环境因素之一.

\section{3 细菌生态功能及其环境意义}

泥炭藓顶端的生长伴随着下部的死亡和缓慢分 解，因此从泥炭藓顶端到下伏泥炭沉积物细菌群落 
组成具有明显变化. 泥炭藓上部优势种群为蓝细菌 门和 $\alpha$ 变形菌门, 泥炭藓顶端光照充分, 大量的蓝细 菌光合作用伴随着泥炭藓植株的生长. 多个文库中 均发现蓝细菌门克隆子, 在 SP1 中的相对丰度达 $35 \%$. 前人研究也在泥炭藓中检测到蓝细菌门克隆子的存 在, 为蓝细菌和泥炭藓的共生提供了证据(Morales 等, 2006; Kip 等, 2012; 刘乔等, 2013). 有趣的是, 在位 于地面以下 $25 \mathrm{~cm}$ 处的 SD3 中也发现了蓝细菌门的 克隆, 由于该采样深度没有阳光, 蓝细菌很可能是来 自沉积物中没有降解的泥炭藓残留, 说明蓝细菌的 DNA 在酸性泥炭湿地的条件下可以保存一定的时间. 由于蓝细菌在自然界中分布广泛、对环境变化响应灵 敏, 再加上其漫长的演化历史, 蓝细菌尤其是其生物 标记物在古环境演变以及生物灭绝模式探讨中得到 了重要应用, 如利用蓝细菌生物标记物 $\mathrm{C}_{31}$ 二甲基蕉 烷成功揭示了蓝细菌繁盛与无脊椎动物灭绝的耦合 关系(Xie 等, 2005). 泥炭沉积物中蓝细菌 DNA 的成 功扩增则有可能为研究泥炭湿地古环境演变提供除 生物标志化合物以外的新途径, 值得进一步深入研 究.

地表以下的两个泥炭沉积物样品长期处于淹水 的缺氧环境, 植株残体不易分解而直接碳化(包文美 和曹建国, 2001), 酸杆菌门是细菌群落中的优势类群. 据研究, 酸杆菌门是根系土壤中相对丰度最大, 活性 最高的门类(Lee 等, 2008), 且从酸性泥炭湿地分离出 来的若干酸杆门的菌株能降解泥炭藓细胞壁特有的 半乳糖醛酸(Pankratov 等, 2008). 因此, 大九湖泥炭 沉积物中酸杆菌对泥炭藓的降解应该起到了重要作 用, 同时也可能是导致泥炭地酸性条件的重要微生 物类群. 近年来, 人们还发现酸杆菌门的细菌能合成 细菌支链甘油二烷基甘油四醚(GDGT)(Weijers 等, 2009; Peterse 等, 2010), 而 GDGT 在陆地古温度重建 上具有重要作用(谢树成等, 2013). 此次研究的泥炭 沉积物中酸杆菌的平均相对丰度为 $42.3 \%$, 其 GDGT
在重建大九湖地区古温度变化中具有很大的潜力.

尤其值得指出的是, 此次研究中共发现 15 个属 于甲基孢囊菌科克隆子, 且在各个样品中均有分布. 其下属的甲基孢囊菌属为 II 型甲烷氧化菌, 利用丝 氨酸途径氧化甲烷参与碳循环过程. 在酸性林地 (Radajewski 等, 2002)、水稻土(Hoffmann 等, 2002)和 泥炭藓透明细胞中(Raghoebarsing 等, 2005)等都有发 现. 甲基孢囊菌属是酸性泥炭湿地中数量占优势、且 新陈代谢活跃的甲烷氧化类群(Belova 等, 2011). 沉 积物有机质降解释放的甲烷为甲烷氧化菌提供碳源 和能源, 泥炭藓植株的透明细胞能够为甲烷化菌提 供微环境, 而甲烷氧化菌氧化甲烷产生的 $\mathrm{CO}_{2}$ 可作 为植物光合作用的原料(Raghoebarsing 等, 2005), 因 此甲烷氧化菌通过与泥炭藓共生从而在泥炭湿地的 $\mathrm{CH}_{4}$ 循环中起到介导作用, 进而对泥炭湿地的 $\mathrm{CH}_{4}$ 循 环和通量产生影响.

\section{4 结论}

大九湖湿地泥炭藓植株及下伏泥炭沉积物均含 有丰富的细菌, 细菌 $16 \mathrm{~S}$ rRNA 基因丰度在 $10^{8}$ 个拷 贝/克样品. 群落结构总体上以酸杆菌门和变形菌门 为主, 这与大九湖泥炭湿地的酸性条件密切相关. 细 菌群落组成从泥炭藓的上部到泥炭沉积物底部有显 著变化, 泥炭藓上部以蓝细菌门和 $\alpha$ 变形杆菌门为主, 中部以酸杆菌门为主, 地表附近样品以 $\alpha$ 变形菌为主, 地表以下沉积物中细菌以酸杆菌门为主. 蓝细菌主 要位于泥炭举的上部, 通过光合作用与泥炭藓共生, 而酸杆菌门则因具有分解泥炭藓细胞壁特定物质的 能力而在泥炭藓降解及碳化过程中发挥重要作用. 值得注意的是, 甲基孢囊菌科在泥炭藓不同部位均 有发现, 表明泥炭藓不同部位均存在甲烷氧化, 这进 一步深化了泥炭湿地中甲烷氧化菌与泥炭藓共生关 系的认识.

\section{参考文献}

包文美，曹建国. 2001. 泥炭藓及其孢子萌发和有性生殖. 生物学通报, 36: 8-9

戴雅婷, 侯向阳, 王慧, 等. 2012. 鄂尔多斯沙地油蒿根际土壤微生物数量的季节动态. 干旱区资源与环境, 10: 103-107

何报寅, 张穗, 蔡述明. 2003. 近 2600 年神农架大九湖泥炭的气候变化记录. 海洋地质与第四纪地质, 23: 109-115

刘乔, 王红梅, 龚林锋, 等. 2013. 湖北神农架大九湖泥炭地泥炭藓共生细菌群落分析. 第四纪研究, 33: 79-87

石敏, 喻建新, 顾延生, 等. 2008. 神农架大九湖晚更新世与全新世之交的气候变化——来自孢粉的信息. 地质科技情报, 27: 24-28 
汪良驹, 刘友良. 1998. 植物细胞中的液泡及其生理功能. 植物生理学通讯, 34: 394-400

谢树成, 黄咸雨, 杨欢, 等. 2013. 示踪全球环境变化的微生物代用指标. 第四纪研究, 33: 1-18

杨丽阳, 吴䒯, 黄俊华, 等. 2009. 大九湖泥炭柱样的木质素特征. 地球化学, 38: 133-139

袁红朝, 秦红灵, 刘守龙, 等. 2011. 长期施肥对红壤性水稻土细菌群落结构和数量的影响. 中国农业科学, 44: 4610-4617

朱诚, 马春梅, 张文卿, 等. 2006. 神农架大九湖 $15.753 \mathrm{kaB} . P$. 以来的狍粉记录和环境演变. 第四纪研究, 26: 814-826

Augustin J, Merbach W, Schmidt W, et al. 1996. Effect of changing temperature and water table on trace gas emission from minerotrophic mires. J Appl Bot-Angew Bot, 70: 45-51

Ausec L, Kraigher B, Mandic-Mulec I. 2009. Differences in the activity and bacterial community structure of drained grassland and forest peat soils. Soil Biol Biochem, 41: 1874-1881

Belova S E, Baani M, Suzina N E, et al. 2011. Acetate utilization as a survival strategy of peat-inhabiting Methylocystis spp. Environ Microbiol Rep, 3: 36-46

Bossio D A, Scow K M, Gunapala N, et al. 1998. Determinants of soil microbial communities: Effects of agricultural management, season, and soil type on phospholipid fatty acid profiles. Microbial Ecol, 36: 1-12

Bridgham S D, Pastor J, Janssens J A, et al. 1996. Multiple limiting gradients in peatlands: A call for a new paradigm. Wetlands, 16: 45-65

Chao A. 1984. Nonparametric estimation of the number of classes in a population. Scand J Stat, 11: 265-270

Dedysh S N, Pankratov T A, Belova S E, et al. 2006. Phylogenetic analysis and in situ identification of bacteria community composition in an acidic Sphagnum peat bog. Appl Environ Microbiol, 72: 2110-2117

Falkowski P G, Fenchel T, Delong E F. 2008. The microbial engines that drive Earth's biogeochemical cycles. Science, 320: 1034-1039

Fierer N, Jackson R B. 2006. The diversity and biogeography of soil bacterial communities. Proc Natl Acad Sci USA, 103: 626-631

Gibbon B C, Kropf D L. 1993. Intracellular pH and its regulation in Pelvetia zygotes. Dev Biol, 157: 259-268

Gorham E. 1991. Northern peatlands: Role in the carbon cycle and probable responses to climatic warming. Ecol Appl, 1: 182-195

Gorham E. 1995. The biogeochemistry of northern peatlands and its possible responses to global warming. In: Woodwell G M, Mackenzie F T, eds. Biotic Feedback in the Global Climatic System. New York: Oxford University Press. 169-187

Gürtler V, Stanisich V A. 1996. New approaches to typing and identification of bacteria using the 16S-23S rDNA spacer region. Microbiology, 142: 3-16

Heck Jr K L, van Belle G, Simberloff D. 1975. Explicit calculation of the rarefaction diversity measurement and the determination of sufficient sample size. Ecology, 56: 1459-1461

Hoffmann T, Horz H, Kemnitz D, et al. 2002. Diversity of the particulate methane monooxygenase gene in methanotrophic samples from different rice field soils in China and the Philippines. Syst Appl Microbiol, 25: 267-274

Huang X, Wang C, Zhang J, et al. 2011. Comparison of free lipid compositions between roots and leaves of plants in the Dajiuhu Peatland, central China. Geochem J, 45: 365-373

Hughes J B, Hellmann J J, Ricketts T H, et al. 2001. Counting the uncountable: Statistical approaches to estimating microbial diversity. Appl Environ Microbol, 67: 4399-4406

Humayoun S B, Bano N, Hollibaugh J T. 2003. Depth distribution of microbial diversity in Mono Lake, a meromictic soda lake in California. Appl Environ Microbol, 69: 1030-1042

Jackson C R, Liew K C, Yule C M. 2009. Structural and functional changes with depth in microbial communities in a tropical Malaysian peat swamp forest. Microb Ecol, 57: 402-412

Janssen P H. 2006. Identifying the dominant soil bacterial taxa in libraries of 16S rRNA genes. Appl Environ Microbol, 72: 1719-1728

Kim J, Sparovek G, Longo R M, et al. 2007. Bacterial diversity of terra preta and pristine forest soil from the Western Amazon. Soil Biol Biochem, 39: 684-690

Kip N, Fritz C, Langelaan E S, et al. 2012. Methanotrophic activity and diversity in different Sphagnum magellanicum dominated habitats in the southernmost peat bogs of Patagonia. Biogeosciences, 9: 47-55

Kraigher B, Stres B, Hacin J, et al. 2006. Microbial activity and community structure in two drained fen soils in the Ljubljana Marsh. Soil Biol Biochem, 38: 2762-2771

Lee S H, Ka J O, Cho J C. 2008. Members of the phylum Acidobacteria are dominant and metabolically active in rhizosphere soil. FEMS Microbiol Lett, 285: 263-269

Männistö M K, Tiirola M, Häggblom M M. 2007. Bacterial communities in Arctic fjelds of Finnish Lapland are stable but highly pH-dependent. FEMS Microbiol Ecol, 59: 452-465

Morales S E, Mouser P J, Ward N, et al. 2006. Comparison of bacterial communities in New England Sphagnum bogs using terminal restriction 
fragment length polymorphism (T-RFLP). Microbial Ecol, 52: 34-44

Muyzer G, Smalla K. 1998. Application of denaturing gradient gel electrophoresis (DGGE) and temperature gradient gel electrophoresis (TGGE) in microbial ecology. Anton Leeuw, 73: 127-141

Nadkarni M A, Martin F E, Jacques N A, et al. 2002. Determination of bacterial load by real-time PCR using a broad-range (universal) probe and primers set. Microbiology. 148: 257-266

Pankratov T A, Serkebaeva Y M, Kulichevskaya I S, et al. 2008. Substrate-induced growth and isolation of Acidobacteria from acidic Sphagnum peat. ISME J, 2: 551-560

Peterse F, Nicol G W, Schouten S, et al. 2010. Influence of soil pH on the abundance and distribution of core and intact polar lipid-derived branched GDGTs in soil. Org Geochem, 41: 1171-1175

Radajewski S, Webster G, Reay D S, et al. 2002. Identification of active methylotroph populations in an acidic forest soil by stable-isotope probing. Microbiology, 148: 2331-2342

Raghoebarsing A A, Smolders A J, Schmid M C, et al. 2005. Methanotrophic symbionts provide carbon for photosynthesis in peat bogs. Nature, 436: $1153-1156$

Roberts J K, Ray P M, Wade-Jardetzky N, et al. 1980. Estimation of cytoplasmic and vacuolar pH in higher plant cells by 31P NMR. Nature, 283: 870-872

Sait M, Davis K E, Janssen P H. 2006. Effect of pH on isolation and distribution of members of subdivision 1 of the phylum Acidobacteria occurring in soil. Appl Environ Microbl, 72: 1852-1857

Schopf J W, Kudryavtsev A B, Agresti D G, et al. 2002. Laser-Raman imagery of Earth's earliest fossils. Nature, 416: 73-76

Shen J, Zhang L, Guo J, et al. 2010. Impact of long-term fertilization practices on the abundance and composition of soil bacterial communities in Northeast China. Appl Soil Ecol, 46: 119-124

Wang M, Ahrné S, Jeppsson B, et al. 2005. Comparison of bacterial diversity along the human intestinal tract by direct cloning and sequencing of 16S rRNA genes. FEMS Microbiol Ecol, 54: 219-231

Weijers J W, Panoto E, van Bleijswijk J, et al. 2009. Constraints on the biological sources of the orphan branched tetraether membrane lipids. Geomicrobiology J, 26: 402-414

Xie S, Evershed R P, Huang X, et al. 2013. Concordant monsoon-driven postglacial hydrological changes in peat and stalagmite records and their impacts on prehistoric cultures in central China. Geology, 41: 827-830

Xie S, Pancost R D, Yin H, et al. 2005. Two episodes of microbial change coupled with Permo/Triassic faunal mass extinction. Nature, 434: 494-497 